\title{
Editorial: 2021, the Year of Returning to Normalcy.... Hopefully
}

\author{
Stephen Scypinski ${ }^{1}$
}

Published online: 1 March 2021

(c) The Author(s), under exclusive licence to Springer Science+Business Media, LLC part of Springer Nature 2021

Dear Readers of the Journal of Pharmaceutical Innovation

Our $29^{\text {th }}$ President, Warren Harding, campaigned over a hundred years ago in 1920 about a "return to normalcy" (a word he coined himself) after the conclusion of World War I. Today's events provide an almost eerie throwback to those early years of the twentieth century. 2020 for many of us is almost a blur but events of the past weeks suggest that things may be turning around. I am sure all who are reading this have close colleagues, friends and family members who have received the COVID-19 vaccine. To this end, I must say my faith and confidence in the pharmaceutical industry is upheld. Let us all hope the path we are embarking on will restore the world we knew to its former state.

Enough about philosophy. The Journal of Pharmaceutical Innovation continues to drive forward with articles that portray the cutting-edge mentality being displayed in both industry and academia. Consider the latest issue in the pages following this editorial. You will find manuscripts that outline perspectives on flexible manufacturing, various approaches such as micronization and nanoparticle technology for enhancing bioavailability of low-solubility drugs, and several articles that describe innovative formulation methods. It is no secret that the molecules emanating from medicinal chemistry laboratories, the National Institute of Health, and Academic Research Organizations are more complex and challenging than those of even 5 years ago. This journal remains committed to serving the needs of scientists who seek to utilize the power of published research to help advance important medicines to patients who need them. Our lineup of articles testifies to this commitment.

I have stated this my past several editorials, but it bears $s$ repeating. This is YOUR journal and as such fosters an open dialog with its readers and subscribers. If you have any suggestions, comments, and even criticisms I want to hear from you. My email address is sscypinski@comcast.net. Until our next issue, I wish you to all stay safe.

Publisher's Note Springer Nature remains neutral with regard to jurisdictional claims in published maps and institutional affiliations.

Stephen Scypinski

sscypinski@comcast.net

1 Pharmaceutical Technology, Daiichi Sankyo, Inc, Basking Ridge, NJ, USA 